\title{
Reformado de glicerol con vapor de agua usando catalizador de níquel
}

\author{
M. Yus., J. Soler., M. Menéndez \\ Catalysis, Molecular Separations and Reactor Engineering Group (CREG) \\ Instituto de Investigación en Ingeniería de Aragón (I3A) \\ Universidad de Zaragoza, Mariano Esquillor s/n, 50018, Zaragoza, Spain. \\ Tel.+34-876555486, Fax+34-976762043, e-mail: miryusm@unizar.es
}

\begin{abstract}
Durante la transesterificación de los triglicéridos para la obtención de biodiesel se produce aproximadamente un $10 \%$ en peso de glicerol. Debido al incremento de producción de biodiesel, se ha generado un exceso de glicerol que el mercado no ha sido capaz de asumir, por lo que el precio de este polialcohol ha caído. Es por esto que se están buscando nuevas utilidades, siendo su uso para producir hidrógeno una aplicación que podría consumir una gran cantidad de glicerol. Acorde con este planteamiento, se ha estudiado el reformado de glicerol con vapor de agua en un reactor de lecho fijo (10 mm de diámetro interno) empleando catalizador $\mathrm{Ni} / \mathrm{Al}_{2} \mathrm{O}_{3}$, cargado con $1 \%$ en peso de $\mathrm{Ni}$. El caudal de glicerol ha sido de 2,8 L/h.kg de catalizador, y se ha introducido nitrógeno como gas de arrastre. Las relaciones molares entre agua y glicerol ensayadas han sido de 9:1 y 3:1 y la temperatura se ha variado entre 600 y 700 ㄷ. Los gases a la salida del reactor se han analizado mediante un cromatógrafo de gases en línea, y se han ido tomando muestras líquidas a lo largo de cada experimento, que también se analizaron posteriormente mediante cromatografía de gases. El coque depositado sobre el catalizador a lo largo de la reacción se ha cuantificado mediante análisis termogravimétrico (TGA). Finalmente, el objetivo de estos experimentos es encontrar las mejores condiciones de operación para ensayarlas en un reactor de lecho fluidizado de dos zonas, para operar el proceso en estado estacionario.
\end{abstract}

